\section{Canadian psychiatry}

DEAR SIRS

The article 'English Psychiatrist in Ontario' by Dr John L. Crammer was interesting but did not give a true picture of the state of psychiatry in Canada. I had the privilege of working on both sides of the Atlantic and, during my first year in Canada, thought that everything in the field of psychiatry should be like Britain. But, the truth is that Canadian psychiatry in all variations-practice, research, academics, and administration-is not a clone of British psychiatry. Dr Crammer's observation on obesity and water intoxication were surprising. In 15 years of practice in Canada I came across obese women and men patients but not a single case of water intoxication.

Dr Crammer's observation on alcoholism is not factual. The consumption in Canada in litres (per inhabitant) of wine is 8.5 and for beer 87.6 and in the UK, 7.2 for wine and 117.1 for beer. Many years ago Sir William Osler said, "Throw all the beer and spirits into the Irish Channel, the English Channel, and the North Sea for a year and people in England would be infinitely better. It would certainly solve all the problems with which the philanthropist, the physicians and the politicians have to deal".

Dr Crammer, I hope will agree that the scope of psychotherapy remains enormous and that patients in Canada have ready access to psychiatrists. In Ontario they do not have to be screened by the family physician all the time as in Britain. This system has disadvantages but proves mainly beneficial to the patient.

Dr Mark Aveline, in his article 'What Price Psychiatry Without Psychotherapy'1, wrote that psychotherapy was a new specialty in the NHS and that "Human problems in relationship require human remedies, that is, a therapeutic relationship which leads the patient to correct self destructive patterns involved in the past".

Dr Crammer wrote, "Well of course psychiatric treatment may relieve unhappiness-to overcome disabilities, etc." I fail to understand the implication of this statement. Did Dr Crammer mean that psychotherapy was underutilised in patient care in Britain? He added, "There has been little interest in intensive psychotherapy-for which many patients as screened by GPs seemed unsuited". General practitioners often don't have enough psychodynamic background or the knowledge of psychopathology. I wonder if this practice is good medicine.

Dr Crammer, while comparing the Ontario Health Insurance Plan with the British National Health Service, commented "Doctors are not expected to collaborate in the individual's care hence the fact that some Canadian GPs will go away from it for a time and leave the care of their patient emergency-then repercussion on the family". I agree with this but usually the referring physician phones me to give adequate background information about the patient. According to the Ontario Health Insurance Plan, consulting psychiatrists have to send written reports to the referring physician.

Dr Crammer who himself was disappointed with the
British system said, "But who do you approach in such a campaign. Twenty-four years as a consultant in the National Health Services showed me over and over again that it is often very difficult to find out who "if anyone" is in charge. Who is actually responsible for that category of decision in the National Health Service and which way the chain of responsibility runs. If you can identify the responsible person you can write to them or speak with them. In the National Health Service it is more like writing to Santa Claus." I feel the Canadian situation is much healthier in this respect. Also, I do agree with Dr Crammer that on this side of the Atlantic we have to spend a lot of time in documentation.

Dr Crammer's observation on psychiatric care for rural populations in Canada was very pertinent.

Dr Crammer did not make any observation on peer review in England but I feel, while Canadian and North American psychiatry has made substantial progress in this area, it is still in its infancy in Britain.

Finally, I wish to quote from More for the Mind ${ }^{3}$, a study of psychiatric services in Canada which was published in 1963. It stated in epilogue, "Mental health transcends medical concern with sickness and health. It relates to the whole spectrum of organized social living. It has to do not only with spotting and treating children with mental health problems in the school but with the whole fabric of the school itself. It has to do not only with the neurotic and character disorder of adults in the community but with their marital, occupational and social needs. Thus the mental health problem of the community while having an important psychiatric aspect, will not be resolved suocessfully by psychiatric planning alone. It will involve careful joint study and planning with many professional disciplines including among others, Psychology, Education, Social Work, Theology and the Law". They were not just recommendations written 23 years ago but played a major role in the evolution of psychiatry in this country.

The Homewood Sanitarium of Guelph, Ontario, Limited

Delhi Street, Guelph, Ontario Canada

\section{Rarerences}

'Avelne, MARx (1984) What price peychiatry without paychotherapy? Lancet, II, 856-858.

${ }^{2}$ Canmoger, J. L. (1986) An English poychiatrist in Ontario. Bulletin of the Royal Colloge of Psychiatrists, 11, 315-316.

${ }^{3}$ Tyhusest, J. S., Chalxe, F. C. R., Lawson, F. S., McNeel, B. H., Roberts, C. A., Tanlor, G. C., Wen, R. J. \& Grifrin, J. D. (1963) More for the Mind. Canadian Mental Health Association, National Office, $11 \frac{1}{2}$ Spadina Road, Toronto 4.

\section{Dear Strs}

As a medical specialist in psychiatry my experience and training are supposed to fit me for (1) preventing the death of the suicidal; (2) calming the excited, disturbed and violent; (3) diagnosing a whole range of illnesses with behavioural, affective, cognitive, or perceptual symptoms, which impose disabilities on their sufferers; (4) using drugs 
in treatment of the same; (5) using a variety of psychological methods in treatment of the same; (6) re-introducing (rehabilitating) sufferers into normal daily life. It is a waste of time and training for me to act as a careers adviser, marriage counsellor, or be friendly to people who are not ill but facing one of the hardships that crop up in every normal life from time to time. The fact that people are willing to pay me for my advice, counselling, or friendship is neither here nor there; but some other facts are more relevant.

Psychiatrists are in short supply for the amount of illness and disability that exists in the world. A given population can only produce a finite (rather small) number of trained psychiatrists, because only a limited number of people have the requisite abilities, and some of them must become engineers, scientists, lawyers, administrators, etc. and not doctors, let alone psychiatrists (and student vacancies for the long training are limited also). However, the population may also produce professional and voluntary counsellors of various sorts, some requiring only very short training, and tapping to some extent a different range of abilities.

In Britain (even before the National Health Service began) general practitioners guided patients to the appropriate specialist, and the specialist psychiatrist sees only patients selected by GPs, and then works with the GPs in treating them. This seems to me a more efficient use of the specialist and a better service to the patient than the Canadian open door, where each doctor works independently and the patient can shop around as he fancies and can afford. This also involves the old debate: does psychiatry touch all aspects of life, or is its function limited? Which kind of work do you most enjoy doing?

Department of Psychiatry

The Chinese University of Hong Kong

Prince of Wales Hospital, Shatin, NT, Hong Kong

\section{J. L. Crammer}

\section{Competition in mental health care \\ DeAr Sirs}

In the Bulletin of October $1986(10,262-265)$ you published an article by Dr M. Peet, entitled 'Network Community Mental Health Care in North-West Derbyshire'. I would like to compare the experience in The Netherlands with the network system as described by Peet.

Although the network system in the Netherlands was already operating in the thirties, it was composed of small institutions working separately from each other, offering services for different patient populations - adult psychiatric patients, alcohol and drug addicts, patients with psychosomatic disorders, the demented elderly and psychiatrically ill children.

In this system there were also small institutions offering different services for the same populations for instance, crisis intervention, rehabilitation services, psychotherapy and marital counselling.

Since January 1982 these services have been integrated into one institution per health care region for a population of $\pm 200,000$. These services are founded by means of a population-wide social security law. At the same time two mental health case registers were in operation, one in the North and one in South of The Netherlands.

With these instruments it will be possible to enter census data for a geographically defined area and compare different areas. Our experience from these data is that the total amount of mental health care consumption does not differ much between regions but that the difference between regions is primarily made up by a difference in services offered and used. In our opinion, this indicates that it is quite possible to use alternatives in mental health care services, as Peet indicates.

In The Netherlands the effect on hospital admission is not as striking as mentioned in Peet's article. This is mainly because in The Netherlands the two broad conceptual models of community care, 'the hive system' (representing the hospital as the centre of activities) and the 'network system' (emphasising the development of a network of community services), are working separately from each other in each health care region. This provokes competition in keeping patients: a part of the patients referred from the 'network system' into the 'hive system' do not return to the network system, and this was found in the Northern region as well as the Southern region. The net loss of the network system in a year is 75 patients.

\section{Department of Social Psychiatry}

M. A. J. ROMage

University of Limburg

Maastricht, The Netherlands

\section{Repenences}

'Ten horn, G. H. M. M., Gel, R., Cunamlunatt, W. H. \& Henderson, J. H. (eds) (1986) Psychiatric Case Registers 1960-1985. Amsterdam: Elsevier.

${ }^{2}$ Hamers, H. J. F. R., Romace, M. A. J. \& deVries, M. W. (1986) Resistance, privacy and tochnology: comments on the negotiations of the case register in Maastricht. In Psychiatric Case Registers 1960-1985 (eds Ten Horn, G. H. M. M., Giel, R., Cummblinatt, W. H. and Henderson, J. H.) Amsterdam: Elsevier.

\section{DeAr SIRS \\ Human beings and knowledge}

I wonder if any of your readers would be interested in ancient Eastern comments on the relationship between human beings and knowledge. The following are quotations from Chuang Tsu, a follower of Lao Tsu the founder of Taoism, who lived in the fourth century B.C.

"Life has a limit, but knowledge is without limit. For the limited to pursue the unlimited is futile"."

"Great knowledge is all encompaseing small knowledge is limited. Great words are inspiring; small words are chatter. When we are asleep, we are in touch with our souls. When we are awake, our senses open. We get involved with our activities and our minds are distracted. Sometimes we are hesistant, sometimes underhanded, and sometimes secretive. Little fears cause anxiety, and great fears cause panic. Our words fly of like arrows, as though 